University of Wollongong

Research Online

Faculty of Engineering and Information

Faculty of Engineering and Information

Sciences - Papers: Part A

Sciences

2002

\title{
Mechanically alloyed amorphous Ti50(Cu0.45Ni0.55)44-x AlxSi4B2 alloys with supercooled liquid region
}

\author{
L C. Zhang \\ University of Wollongong, laichang@uow.edu.au \\ Jian Xu \\ Chinese Academy of Sciences \\ E Ma \\ Johns Hopkins University
}

Follow this and additional works at: https://ro.uow.edu.au/eispapers

Part of the Engineering Commons, and the Science and Technology Studies Commons

Research Online is the open access institutional repository for the University of Wollongong. For further information contact the UOW Library: research-pubs@uow.edu.au 


\title{
Mechanically alloyed amorphous Ti50(Cu0.45Ni0.55)44-x AlxSi4B2 alloys with supercooled liquid region
}

\author{
Abstract \\ A high-energy ball milling procedure has been developed to produce amorphous alloys in \\ $\mathrm{Ti}_{50}\left(\mathrm{Cu}_{0.45} \mathrm{Ni}_{0.55}\right)_{44-} \mathrm{Al}_{x} \mathrm{Si}_{4} \mathrm{~B}_{2}(x=0,4,8,12)$ powder mixtures. The milling products were characterized \\ using $x$-ray diffraction, differential scanning calorimetry, and transmission electron microscopy. The Ti- \\ based amorphous alloy powders prepared through this solid-state process exhibit a well-defined glass \\ transition and a supercooled liquid region $\left(\Delta T_{\mathrm{X}}=64 \mathrm{~K}\right)$ close to the largest achieved so far for Ti-based \\ undercooled melts. The substitution of $\mathrm{Al}$ for $\mathrm{Cu}$ and $\mathrm{Ni}$ has beneficial effects on stabilizing the \\ supercooled liquid. Residual nanocrystals of the $\alpha$ Ti structure are uniformly dispersed in the amorphous \\ matrix. The composite alloy powders offer the potential for consolidation in the supercooled liquid region \\ to bulk lightweight amorphous alloys and the possibility to attain desirable mechanical properties.

\section{Keywords} \\ ti50, region, liquid, alloys, $x$, amorphous, mechanically, 44, 55, cu0, alxsi4b2, supercooled, alloyed, 45ni0 \\ Disciplines \\ Engineering | Science and Technology Studies

\section{Publication Details} \\ Zhang, L. C., Xu, J. \& Ma, E. (2002). Mechanically alloyed amorphous Ti50(Cu0.45Nio.55)44-xAl $\mathrm{Si}_{4} \mathrm{~B}_{2}$ alloys \\ with supercooled liquid region. Journal of Materials Research, 17 (7), 1743-1749.
}




\title{
Mechanically alloyed amorphous $\mathrm{Ti}_{50}\left(\mathrm{Cu}_{0.45} \mathrm{Ni}_{0.55}\right)_{44-x} \mathrm{Al}_{x} \mathrm{Si}_{4} \mathrm{~B}_{2}$ alloys with supercooled liquid region
}

\author{
L.C. Zhang and J. Xu ${ }^{\text {a) }}$ \\ Shenyang National Laboratory for Materials Sciences, Institute of Metal Research, CAS, \\ 72 Wenhua Road, Shenyang, 110016 China \\ E. Ma \\ Department of Materials Science and Engineering, The Johns Hopkins University, \\ Baltimore, Maryland 21218
}

(Received 6 February 2002; accepted 18 April 2002)

\begin{abstract}
A high-energy ball milling procedure has been developed to produce amorphous alloys in $\mathrm{Ti}_{50}\left(\mathrm{Cu}_{0.45} \mathrm{Ni}_{0.55}\right)_{44-x} \mathrm{Al}_{x} \mathrm{Si}_{4} \mathrm{~B}_{2}(x=0,4,8,12)$ powder mixtures. The milling products were characterized using $\mathrm{x}$-ray diffraction, differential scanning calorimetry, and transmission electron microscopy. The Ti-based amorphous alloy powders prepared through this solid-state process exhibit a well-defined glass transition and a supercooled liquid region $\left(\Delta T_{\mathrm{x}}=64 \mathrm{~K}\right)$ close to the largest achieved so far for Ti-based undercooled melts. The substitution of $\mathrm{Al}$ for $\mathrm{Cu}$ and $\mathrm{Ni}$ has beneficial effects on stabilizing the supercooled liquid. Residual nanocrystals of the $\alpha$-Ti structure are uniformly dispersed in the amorphous matrix. The composite alloy powders offer the potential for consolidation in the supercooled liquid region to bulk lightweight amorphous alloys and the possibility to attain desirable mechanical properties.
\end{abstract}

\section{INTRODUCTION}

Multicomponent metallic glasses and their composites have attracted a great deal of attention in recent years. ${ }^{1,2}$ Of particular importance are those amorphous alloys based on light elements such as $\mathrm{Al}, \mathrm{Mg}$, and $\mathrm{Ti}$ that promise high specific strength. For example, ultrahigh tensile fracture strengths $\left(\sigma_{\mathrm{f}}\right)$ of 1800 and $2000 \mathrm{MPa}$ have been reported for melt-spun $\mathrm{Ti}_{50} \mathrm{Ni}_{25} \mathrm{Cu}_{25}$ amorphous ribbon ${ }^{3}$ and melt-extracted $\mathrm{Ti}_{40} \mathrm{Zr}_{10} \mathrm{Cu}_{50}$ amorphous wire, ${ }^{4}$ respectively. Unfortunately, compared with the typical bulk glass-forming Pd-based and Zr-based systems, it has been difficult to prepare lightweight metallic glasses in bulk form. For example, the largest thickness achieved so far for Ti-based multicomponent amorphous alloys using conventional casting methods is only of the order of $1 \mathrm{~mm},{ }^{5,6}$ while those for Pd-based and Zr-based alloys are as large as 75 and $30 \mathrm{~mm}$, respectively. ${ }^{7-9}$

An attractive approach that can potentially lead to bulk lightweight metallic glasses is to exploit the processing flexibility provided by the supercooled liquid region of the multicomponent glasses, defined as the temperature interval $\left(\Delta T_{\mathrm{x}}\right)$ between the glass transition temperature $\left(T_{\mathrm{g}}\right)$ and the onset temperature of crystallization $\left(T_{\mathrm{x}}\right)$. A sizable supercooled liquid region has in fact been reported

a) Address all correspondence to this author. e-mail: jianxu@imr.ac.cn for Ti-based amorphous alloys formed through melt cooling. Recently discovered compositions based on $\mathrm{Ti}_{50} \mathrm{Cu}_{20} \mathrm{Ni}_{24} \mathrm{Si}_{4} \mathrm{~B}_{2}$ exhibit a fairly large supercooled liquid region of the order of $60-70 \mathrm{~K} .^{5,6}$ This opens up the possibility of preparing truly bulk samples through powder processing and subsequent warm consolidation in the supercooled liquid region. ${ }^{10-15}$

Mechanical alloying (MA) of powders is a promising approach, with several distinct advantages. First of all, MA can form amorphous alloys at compositions difficult to alloy and amorphize using melt cooling methods. Second, large quantities of powders can be produced in the relatively inexpensive commercial MA process, with the potential for the fabrication of near net shape components. In addition, MA is extremely powerful in creating uniform dispersions of a strengthening/ductilizing second phase. Such a composite approach is often important and sometimes indispensable for the bulk glasses to attain a useful set of mechanical properties, as demonstrated by Johnson et al. ${ }^{16-18}$ Obviously, for the MA route to be viable, the first challenge is to achieve a supercooled liquid region in the MA powders similar to that observed for samples prepared by solidification of melts. This has been successfully demonstrated for mechanically alloyed amorphous $\mathrm{Zr}-\mathrm{Al}-\mathrm{Cu}-\mathrm{Ni}$ alloys $\left(\Delta T_{\mathrm{x}}\right.$ of the order of $\left.90 \mathrm{~K}^{19-21}\right)$. While a number of binary or ternary Ti-based amorphous alloys have been obtained through the MA route, none of these alloys exhibited a supercooled liquid region. ${ }^{22-27}$ 
In this work, glassy multicomponent $\mathrm{Ti}$ alloys have been processed for the first time through high-energy ball milling of powder blends. $\mathrm{Ti}_{50} \mathrm{Cu}_{20} \mathrm{Ni}_{24} \mathrm{Si}_{4} \mathrm{~B}_{2}$, which is one of the compositions that produced a large supercooled liquid region in melt-spun samples according to Zhang and Inoue, ${ }^{5,6}$ was chosen as the base composition. $\mathrm{Al}$ additions were introduced to replace part of the $\mathrm{Cu}$ and $\mathrm{Ni}$ to further reduce the density of the resulting alloys and improve the thermal stability of the supercooled liquid. Our focus is to achieve a significant supercooled liquid region in mechanically alloyed Ti-based systems. We also discuss the effects of milling and $\mathrm{Al}$ substitution on the supercooled liquid region, as well as the influence of the dispersed residual Ti crystals in the milling product on subsequent processing and eventual mechanical properties.

\section{EXPERIMENTAL}

Commercial elemental powders of $\mathrm{Cu}, \mathrm{Ni}$, and $\mathrm{Al}$ were used as starting materials. The as-received powders have a purity of $99.9 \mathrm{wt} \%$ or better and particle sizes smaller than $45 \mu \mathrm{m}$ ( -325 mesh). To reduce gaseous impurities in $\mathrm{Ti}$ and to ensure the alloying of metalloid elements, elemental pieces of $\mathrm{Ti}, \mathrm{Si}$, and $\mathrm{B}$ with a purity higher than $99.5 \mathrm{wt} \%$ were prealloyed by arc melting under a Ti-gettered argon atmosphere in a water-cooled copper crucible. The prealloyed $\mathrm{Ti}-\mathrm{Si}-\mathrm{B}$ button was then crushed into fragments. The mixture of prealloyed fragments and elemental powders having the desired composition of $\mathrm{Ti}_{50}\left(\mathrm{Cu}_{0.45} \mathrm{Ni}_{0.55}\right)_{44-x} \mathrm{Al}_{x} \mathrm{Si}_{4} \mathrm{~B}_{2}(x=0,4,8,12$; in atomic percentage) together with hardened steel balls was loaded in a hardened steel vial under purified argon atmosphere. A ball-to-powder weight ratio about 5:1 was employed. The ball-milling process was performed in a SPEX 8000 (SPEX Samples Preparation, Metuchen, $\mathrm{NJ}$ ) shaker mill cooled by forced flowing air. For all the samples discussed in this paper, the milling time was fixed at $32 \mathrm{~h}$. This time was chosen on the basis of the results of our prior studies of this system, ${ }^{28}$ to ensure that the milling has proceeded sufficiently long for the samples to reach a steady state but short enough to avoid excessive contamination from the milling media. To confirm the reproducibility of the experimental results, at least three samples have been prepared for each composition.

The ball-milled powders were characterized by $\mathrm{x}$-ray diffraction (XRD) using a Rigaku D/max 2400 diffractometer (Tokyo, Japan) with monochromated $\mathrm{Cu} \mathrm{K}_{\alpha}$ radiation $(\lambda=0.1542 \mathrm{~nm})$. Samples with a weight of about $10 \mathrm{mg}$ were sealed in $\mathrm{Al}$ pans for thermal analysis. The glass transition and crystallization of the milled powders were analyzed in a Perkin-Elmer DSC7 (Shelton, CT) under flowing purified argon. A second run under identical conditions was used to determine the baseline after each run.
Samples for transmission electron microscopy (TEM) were prepared by first embedding the powder particles in a nickel foil via electrodeposition for mechanically thinning and subsequently ion-milling. The conventional TEM observations were carried out in a Hitachi H-800 microscope (Hitachi High-technologies Corp., Ibarakiken, Japan). The high-resolution transmission electron microscopy (HREM) images were obtained using a JEOL JEM-2010 microscope (Tokyo, Japan).

The iron and oxygen contents in the ball-milled products were examined using inductively coupled plasma emission spectroscopy (ICP10P, ARL, Valencia, CA) and a LECO TC-436 system (St. Joseph, MI), respectively, to be $0.90 \pm 0.05$ and $0.38 \pm 0.01 \mathrm{wt} \%$, respectively.

\section{RESULTS}

Figure 1 presents the XRD patterns of the powder mixtures with various compositions $\mathrm{Ti}_{50}\left(\mathrm{Cu}_{0.45} \mathrm{Ni}_{0.55}\right)_{44-x} \mathrm{Al}_{x} \mathrm{Si}_{4} \mathrm{~B}_{2}$ $(x=0,4,8,12)$ after milling for $32 \mathrm{~h}$. A broad diffuse diffraction maximum at $2 \theta=35-55^{\circ}$ is the main feature in all these patterns, suggesting that the alloyed powders are predominantly amorphous. However, crystalline peaks of $\alpha$-Ti phase are still identifiable in the patterns of all alloys even though the milling time has been extended to a steady state for the structural evolution. The amorphous scattering maximum is significantly asymmetric,

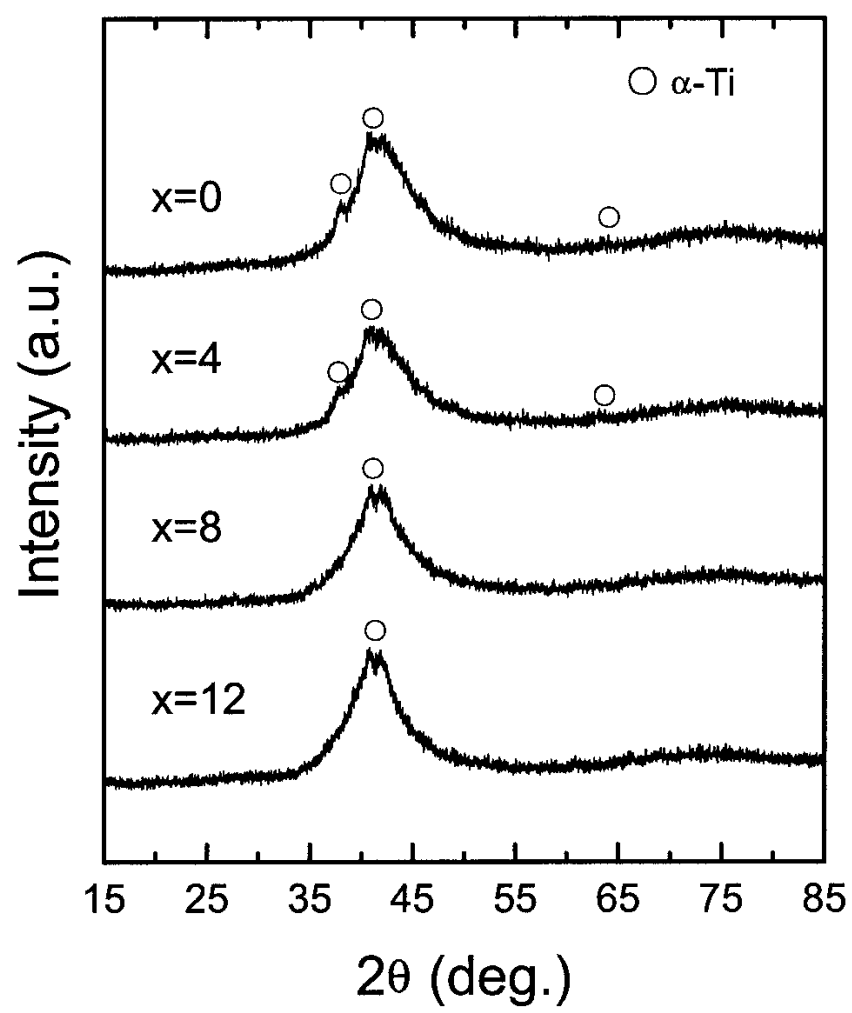

FIG. 1. XRD patterns of the mechanically alloyed powders with the nominal composition of $\mathrm{Ti}_{50}\left(\mathrm{Cu}_{0.45} \mathrm{Ni}_{0.55}\right)_{44-x} \mathrm{Al}_{x} \mathrm{Si}_{4} \mathrm{~B}_{2}(x=0,4,8,12)$. 
which is often a sign that there is a considerable volume fraction of a nanocrystalline phase, with crystallites too small to yield sharp peaks. It was noted that as the $\mathrm{Al}$ content increased, the peak intensity of $\alpha-\mathrm{Ti}$ crystallites was weakened. This is probably caused by the reduction of the volume fraction of the crystalline phase or further refinement of the crystallite grains. In addition, the position of the diffuse diffraction maximum gradually shifted to lower angles with increasing $\mathrm{Al}$ content, consistent with the dissolution of $\mathrm{Al}$ in the alloyed amorphous phase.

Figures 2(a)-2(d) are the TEM bright-field micrographs and corresponding selected area electron diffraction (SAD) patterns of the mechanically alloyed $\mathrm{Ti}_{50}\left(\mathrm{Cu}_{0.45} \mathrm{Ni}_{0.55}\right)_{44-x} \mathrm{Al}_{x} \mathrm{Si}_{4} \mathrm{~B}_{2}$ powders. It was confirmed by TEM observations that there indeed exists residual crystalline phase(s) in all of the milled powders. Also, the chemical composition of these crystals was checked using the energy dispersive $\mathrm{x}$-ray analyzer attached to the TEM. The only major element detected is $\mathrm{Ti}$ with a small amount of $\mathrm{Si}$, without $\mathrm{Cu}$ and $\mathrm{Ni}$. There are no obvious Ti oxide particles on the basis of our SAD patterns for a number of the crystal particles observed. HREM examinations and corresponding diffraction patterns of the crystalline particles, as presented in Fig. 3, reveal that the residual particles are $\alpha-\mathrm{Ti}$, possibly with $\mathrm{B}$ and Si solutes incorporated inside the lattice. With the Al substitution, there appears to be a tendency for an additional refinement of the residual $\alpha-\mathrm{Ti}$ particles. This is consistent with the results of XRD as seen in Fig. 1, where the peak around $2 \theta=38^{\circ}$ for $\alpha-T i$ crystallites is invisible for the alloys at $x=8$ and $x=12$. Also, TEM observation revealed that the majority of the remaining Ti particles are about $10 \mathrm{~nm}$ in size, with an areal fraction of approximately 20\%, as shown in Fig. 2. Changing the $\mathrm{Al}$ content or milling time did not cause obvious changes, except that the number of large particles of $\alpha-\mathrm{Ti}$ phase was reduced.

Figure 4(a) displays the DSC scans in the mode of continuous heating with a heating rate of $40 \mathrm{~K} / \mathrm{min}$ for samples with different $\mathrm{Al}$ contents. In all cases, an endothermic signal associated with the glass transition is evident. Figure 4(b) is an enlarged view of the $x=0$ trace demonstrating the glass transition and the supercooled liquid region, $\Delta T_{\mathrm{x}}$. The onset of glass transition temperature, $T_{\mathrm{g}}$, is apparently insensitive to the change in the overall alloy composition. With increasing $\mathrm{Al}$ substitution, the exothermic reaction due to crystallization occurs at higher temperatures and the single-step crystallization event changes to a two-step process. The heat of crystallization obtained by integrating the area under the peak(s), $\Delta H_{\mathrm{x}}$, is listed in Table I, together with the onset temperature, $T_{\mathrm{x} 1}$, and the peak temperatures, $T_{\mathrm{p}}$, of the crystallization events, as well as the $T_{\mathrm{g}}$ values. Also listed are the widths of $\Delta T_{\mathrm{x}}$. A graphic presentation of these characteristic temperature data is also given in
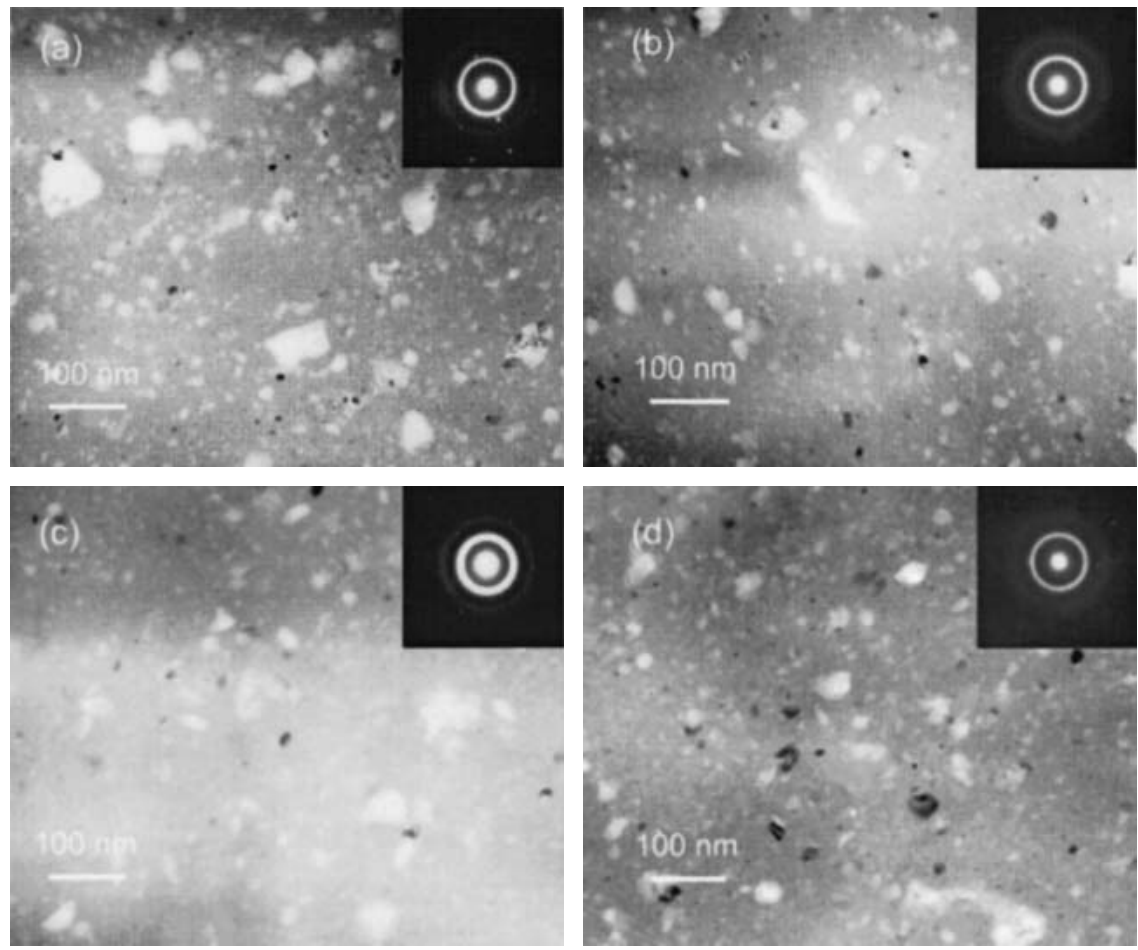

FIG. 2. TEM bright-field micrographs and corresponding electron diffraction patterns (inset) of the mechanically alloyed $\mathrm{Ti}_{50}\left(\mathrm{Cu}_{0.45} \mathrm{Ni}_{0.55}\right)_{44-x} \mathrm{Al}_{x} \mathrm{Si}_{4} \mathrm{~B}_{2}$ powders with different $\mathrm{Al}$ contents: (a) $x=0$; (b) $x=4$; (c) $x=8$; (d) $x=12$. 


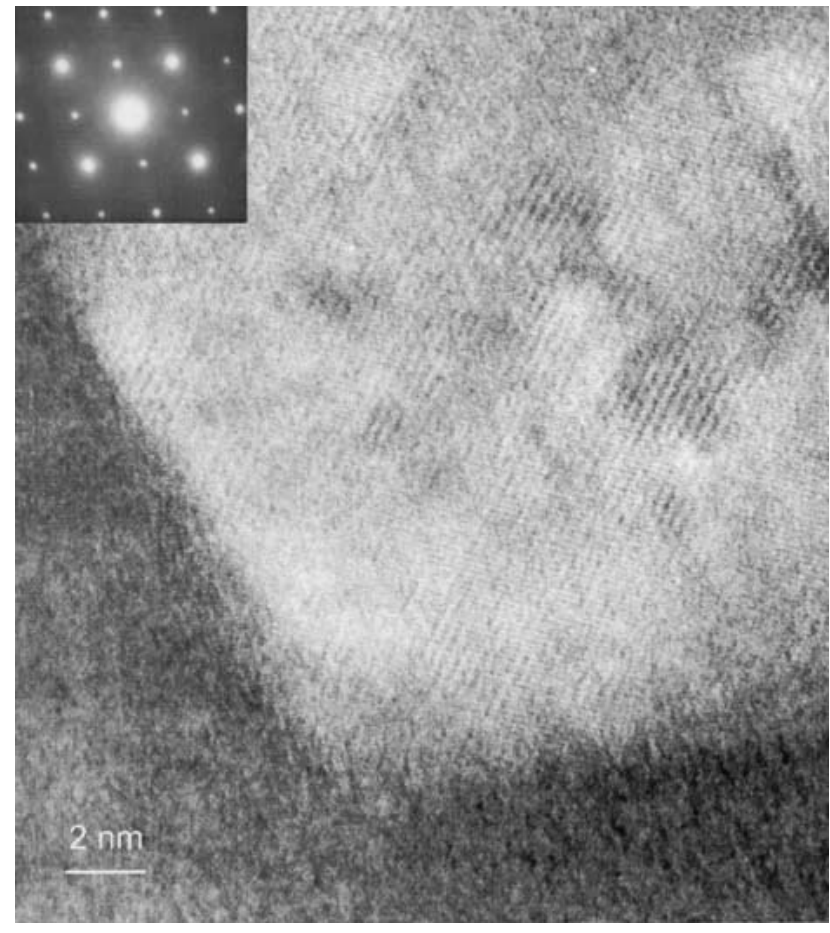

FIG. 3. HREM image and corresponding electron diffraction pattern of a residual crystal embedded in the amorphous matrix of the mechanically alloyed $\mathrm{Ti}_{50}\left(\mathrm{Cu}_{0.45} \mathrm{Ni}_{0.55}\right)_{40} \mathrm{Al}_{4} \mathrm{Si}_{4} \mathrm{~B}_{2}$ powder.

Fig. 5. For comparison purposes, the corresponding data for melt casting Ti-based glasses ${ }^{5,6}$ are included in Table I.

The Al-free base alloy shows a $\Delta H_{\mathrm{x}}$ of $1.30 \mathrm{~kJ} / \mathrm{mol}$. For the melt-spun $\mathrm{Ti}_{50} \mathrm{Cu}_{20} \mathrm{Ni}_{24} \mathrm{~B}_{2}$ amorphous ribbon, the enthalpy of crystallization is not available in Ref. 5. However, the enthalpy of crystallization for the $\mathrm{Ti}_{40} \mathrm{Zr}_{10} \mathrm{Cu}_{50}$ and $\mathrm{Ti}_{45} \mathrm{Zr}_{15} \mathrm{Ni}_{10} \mathrm{Cu}_{30}$ amorphous alloy formed by melt cooling was reported to be 1.71 and $1.75 \mathrm{~kJ} / \mathrm{mol}$, respectively. ${ }^{4,29}$ The present value is somewhat smaller than these findings. One possible source of this discrepancy is that the alloying and amorphization induced by mechanical milling are incomplete, namely, due to the presence of residual crystals, as indicated by XRD analysis and TEM observation. As shown in Fig. 4 and Table I, the samples containing 4-8\% Al showed an extended supercooled liquid region. The largest $\Delta T_{\mathrm{x}}$ reached $64 \mathrm{~K}$, a value comparable with those reported for solidified Ti-based glasses. ${ }^{5,6,30,31}$ Meanwhile, the $\Delta H_{\mathrm{x}}$ also increased for the Al-containing glasses.

Two factors are likely to be responsible for this $\Delta H_{\mathrm{x}}$ increase. A somewhat increased amorphous fraction in the Al-containing samples is a possibility. In addition, when the $\mathrm{Al}$ content exceeds $8 \%$, the crystallization behavior also changed. The XRD patterns in Fig. 6 identify the structural changes associated with the two exothermal events in the DSC traces. The samples were continuously heated to several different temperatures in the DSC, as marked by dots in the curves, and then cooled at
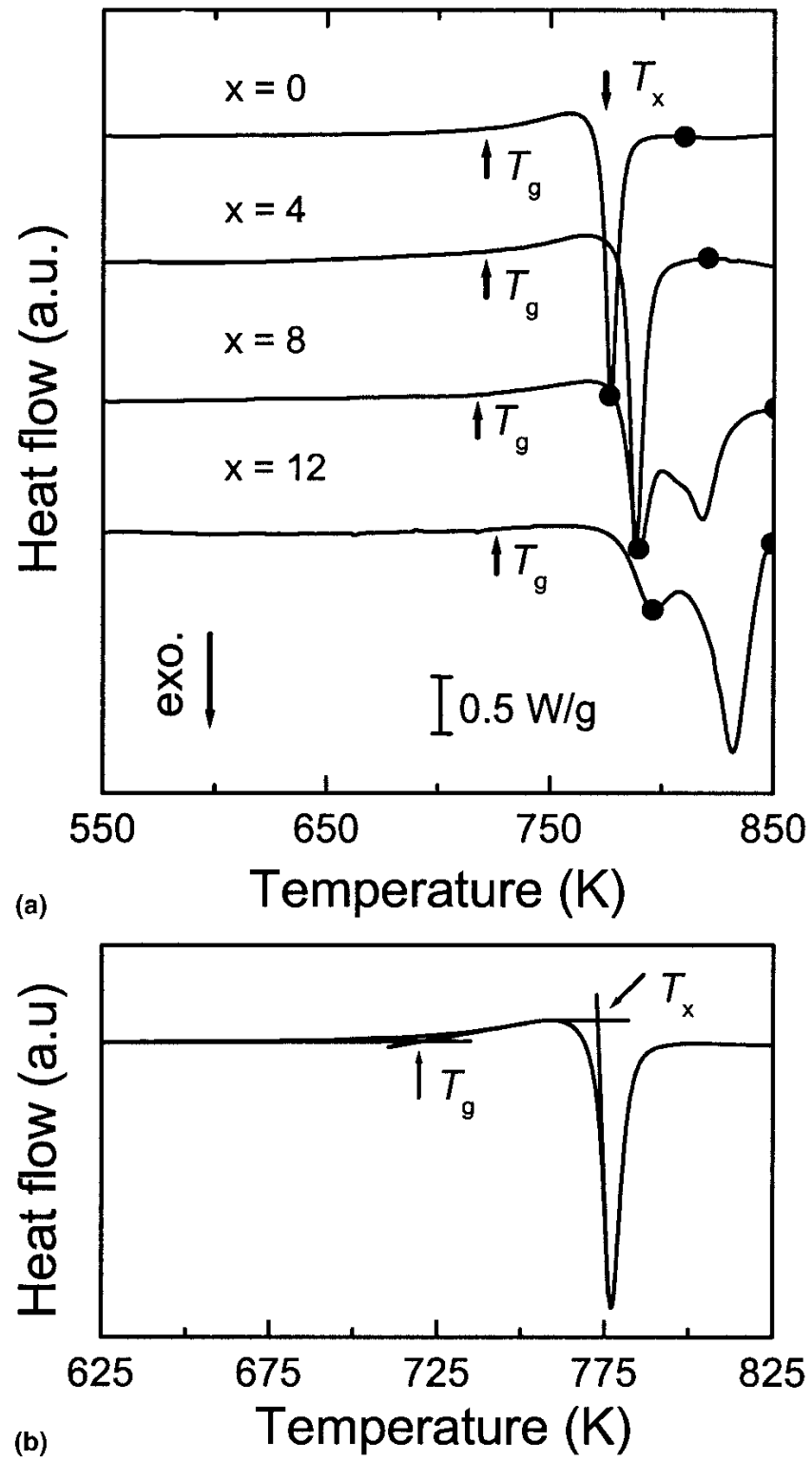

FIG. 4. (a) DSC scans of the mechanically alloyed powders with the nominal composition of $\mathrm{Ti}_{50}\left(\mathrm{Cu}_{0.45} \mathrm{Ni}_{0.55}\right)_{44-x} \mathrm{Al}_{x} \mathrm{Si}_{4} \mathrm{~B}_{2}(x=0,4,8$, 12) (at a heating rate of $40 \mathrm{~K} / \mathrm{min}$ ). (b) An enlarged view of a trace at $x=0$.

$320 \mathrm{~K} / \mathrm{min}$ to room temperature for XRD measurements. For $x=0$, the XRD pattern in Fig. 6(a) at the $777 \mathrm{~K}$ crystallization peak and after the crystallization event $(810 \mathrm{~K})$ showed that the amorphous phase transformed into the cubic NiTi phase and an unknown phase. The same products were found for $x=4$ after crystallization; see the XRD pattern at $820 \mathrm{~K}$ in Fig. 6(b). Such a transition can be regarded as a eutectic-type crystallization, by which the amorphous phase simultaneously transforms into more than two phases in one step. ${ }^{32}$ The lattice parameter of the NiTi phase crystallized in the alloy at $x=0$ was obtained by a Nelson-Riley extrapolation to be $a_{0}=0.3037 \pm 0.0002 \mathrm{~nm},{ }^{33}$ which is about $1.3 \%$ 
larger than that of the binary NiTi phase $\left(a_{0}=0.2998 \mathrm{~nm}\right),{ }^{34}$ possibly implying the presence of additional alloying elements in the NiTi phase. Since the contents of Ni and $\mathrm{Cu}$ in the alloys are essentially equal and the $\mathrm{Ni}$ and $\mathrm{Cu}$ have unlimited mutual solid solubility, it is likely that the $\mathrm{Ni}$ atoms in the NiTi phase can be partially substituted by the $\mathrm{Cu}$ atoms. Consequently, the crystallized NiTi may be expressed as a $(\mathrm{Ni}, \mathrm{Cu}) \mathrm{Ti}$ phase. For $x=8$ and $x=12$, on the other hand, crystallization is completed in two steps. Figure 6 indicates that, in addition to the NiTi phase precipitated in the first stage of the crystallization, the second crystallization peak in the DSC traces arises from the appearance of the $\mathrm{Ti}_{2} \mathrm{Ni}$ intermetallic compounds in the final crystallization products.

\section{DISCUSSION}

This work demonstrates that amorphous $\mathrm{Ti}-(\mathrm{Cu}, \mathrm{Ni}$, $\mathrm{Al})-(\mathrm{B}, \mathrm{Si})$ alloys can be produced through high-energy ball milling of powder blends. A well-defined glass transition well separated from crystallization events has been observed during heating in a differential scanning calorimeter. We have obtained a supercooled liquid region $\left(\Delta T_{\mathrm{x}}\right)$ in the range of 54-64 K. Note that the mechanically alloyed $\mathrm{Ti}-(\mathrm{Cu}, \mathrm{Ni}, \mathrm{Al})-(\mathrm{B}, \mathrm{Si})$ is in fact a nanocomposite, with approximately $20 \mathrm{vol} \% \alpha-\mathrm{Ti}(\mathrm{B}, \mathrm{Si})$ nanocrystals dispersed in the amorphous matrix. The latter thus has a base composition of approximately $\mathrm{Ti}_{42} \mathrm{Cu}_{24} \mathrm{Ni}_{29} \mathrm{Si}_{3} \mathrm{~B}_{2}$, somewhat different from the nominal composition. According to Zhang and Inoue, ${ }^{5}$ their melt-spun alloys at such a composition would still show a $\Delta T_{\mathrm{x}}$ in excess of $50 \mathrm{~K}$, consistent with the $54 \mathrm{~K}$ value observed for our base alloy $(x=0)$.

For a range of $\mathrm{Al}$ contents, the substitution of $\mathrm{Al}$ for $\mathrm{Cu}$ and $\mathrm{Ni}$ appears to enhance the stability of the supercooled liquid region by delaying the first crystallization event, in addition to reducing the density of the resultant alloy. The largest supercooled liquid region observed in our samples is $64 \mathrm{~K}$, close to the values ( 65 to $78 \mathrm{~K}$ ) observed so far for undercooled Ti-based multicomponent melts. ${ }^{5,6,30,31}$ The beneficial effects of $\mathrm{Al}$ seem to stem from the fact that $\mathrm{Al}$ has a large negative heat of mixing with all the major elements involved and a significant size difference from $\mathrm{Cu}$ and $\mathrm{Ni}$. Adding $\mathrm{Al}$ to beyond $x=8$ is no longer helpful, however. These observations are also consistent with the reports of Bonetti et $a l .{ }^{35,36}$ and Cocco et $a l .{ }^{37}$ that an appropriate amount of $\mathrm{Al}$ in $\mathrm{Ti}-\mathrm{Al}$ binary powders destabilizes the crystalline structure upon milling. However, amorphization is no longer favorable when the Al content is excessive: while Ti-rich powders undergo easy amorphization, cubic crystals dominate in the Al-rich samples. ${ }^{35-37}$

The system appears to be prone to incomplete homogenization and amorphization upon mechanical milling. Similar observations have been reported in other easy glass-forming multicomponent systems after MA. For example, the final milling products after MA of $\mathrm{Zr}$ based, Fe-based, and Mg-based multicomponent powders are also comprised of amorphous alloys and residual crystals. $^{21,38-40}$ In fact, the presence of crystals is obvious even from simple $\mathrm{x}$-ray diffraction studies: Bragg peaks are clearly visible in the XRD patterns for all these three systems. This indicates that the completely alloying and amorphization under ball milling in the higher order alloys is more difficult than in conventional binary alloys, even though it was shown that amorphization process by solid-state reaction in $\mathrm{Zr}-\mathrm{Al}-\mathrm{Cu}-\mathrm{Ni}$ system is

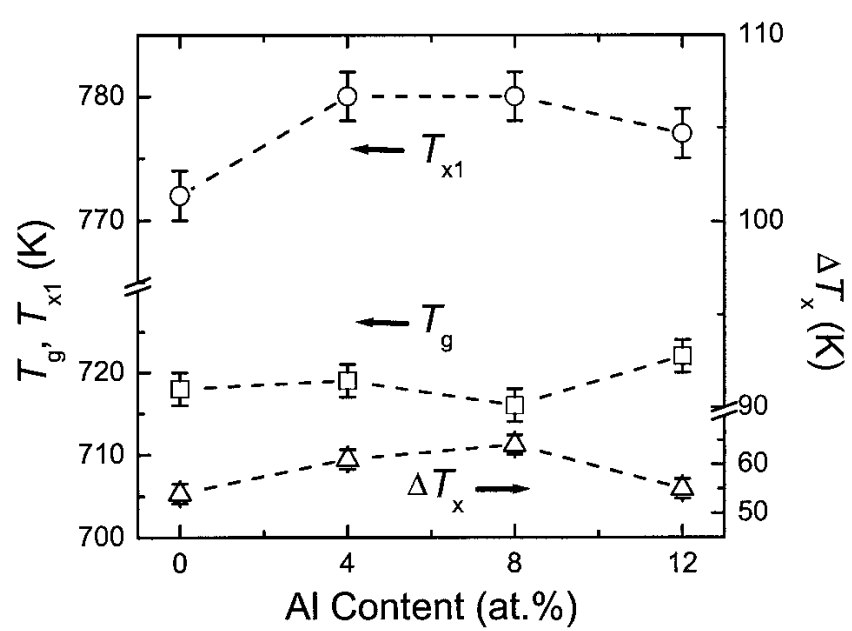

FIG. 5. Glass transition temperature, $T_{\mathrm{g}}$, onset temperature of crystallization, $T_{\mathrm{x} 1}$, and width of supercooled liquid region, $\Delta T_{\mathrm{x}}$, obtained from DSC scans as a function of $\mathrm{Al}$ content for the mechanically alloyed $\mathrm{Ti}_{50}\left(\mathrm{Cu}_{0.45} \mathrm{Ni}_{0.55}\right)_{44-x} \mathrm{Al}_{x} \mathrm{Si}_{4} \mathrm{~B}_{2}$ powders.

TABLE I. Glass transition $\left(T_{\mathrm{g}}\right)$, onset $\left(T_{\mathrm{x} 1}\right)$, and peak $\left(T_{\mathrm{p}}\right)$ temperatures of crystallization, extension of the supercooled liquid region $\left(\Delta T_{\mathrm{x}}\right)$, and total heat release of crystallization $\left(\Delta H_{\mathrm{x}}\right)$ obtained from DSC analysis (heating rate of $40 \mathrm{~K} / \mathrm{min}$ ).

\begin{tabular}{|c|c|c|c|c|c|c|c|c|}
\hline Alloys & $\begin{array}{l}T_{\mathrm{g}} \\
(\mathrm{K})\end{array}$ & $\begin{array}{l}T_{\mathrm{x} 1} \\
(\mathrm{~K})\end{array}$ & $\begin{array}{l}\Delta T_{\mathrm{x}} \\
(\mathrm{K})\end{array}$ & $\begin{array}{l}T_{\mathrm{p} 1} \\
(\mathrm{~K})\end{array}$ & $\begin{array}{l}T_{\mathrm{p} 2} \\
(\mathrm{~K})\end{array}$ & $\begin{array}{c}\Delta H_{\mathrm{x}} \\
(\mathrm{kJ} / \mathrm{mol})\end{array}$ & Method & Ref. \\
\hline $\mathrm{Ti}_{50} \mathrm{Cu}_{20} \mathrm{Ni}_{24} \mathrm{Si}_{4} \mathrm{~B}_{2}$ & $718 \pm 2$ & $772 \pm 2$ & $54 \pm 2$ & $778 \pm 2$ & $\cdots$ & $1.30 \pm 0.10$ & MA & This work \\
\hline $\mathrm{Ti}_{50} \mathrm{Cu}_{18} \mathrm{Ni}_{22} \mathrm{Al}_{4} \mathrm{Si}_{4} \mathrm{~B}_{2}$ & $719 \pm 2$ & $780 \pm 2$ & $61 \pm 2$ & $787 \pm 2$ & $\cdots$ & $1.67 \pm 0.02$ & MA & This work \\
\hline $\mathrm{Ti}_{50} \mathrm{Cu}_{16} \mathrm{Ni}_{20} \mathrm{Al}_{8} \mathrm{Si}_{4} \mathrm{~B}_{2}$ & $716 \pm 2$ & $780 \pm 2$ & $64 \pm 2$ & $789 \pm 2$ & $818 \pm 2$ & $2.96 \pm 0.09$ & MA & This work \\
\hline $\mathrm{Ti}_{50} \mathrm{Cu}_{14} \mathrm{Ni}_{18} \mathrm{Al}_{12} \mathrm{Si}_{4} \mathrm{~B}_{2}$ & $722 \pm 2$ & $777 \pm 2$ & $55 \pm 2$ & $794 \pm 2$ & $830 \pm 2$ & $3.96 \pm 0.07$ & MA & This work \\
\hline $\mathrm{Ti}_{50} \mathrm{Cu}_{20} \mathrm{Ni}_{24} \mathrm{Si}_{4} \mathrm{~B}_{2}$ & 735 & 800 & 65 & $\cdots$ & $\cdots$ & $\ldots$ & Casting & 5 \\
\hline $\mathrm{Ti}_{50} \mathrm{Cu}_{20} \mathrm{Ni}_{24} \mathrm{Sn}_{3} \mathrm{Si}_{2} \mathrm{~B}_{1}$ & 726 & 800 & 74 & $\cdots$ & $\cdots$ & $\ldots$ & Casting & 6 \\
\hline
\end{tabular}




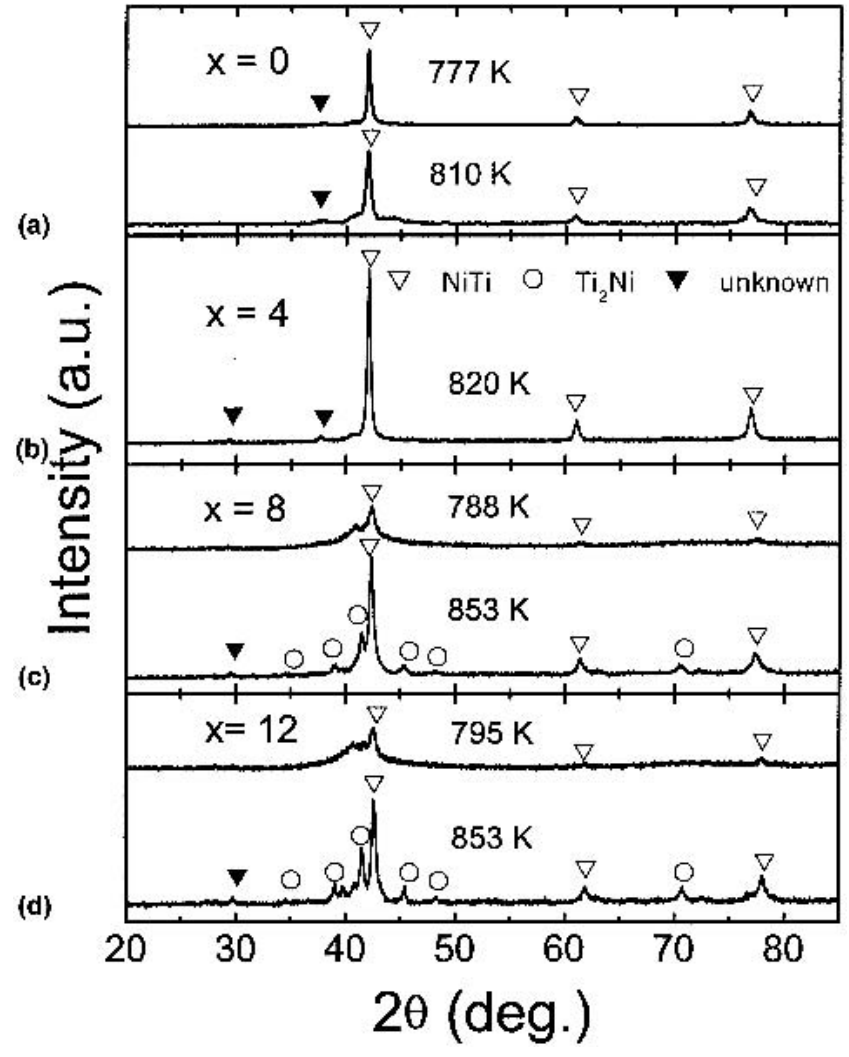

FIG. 6. XRD patterns measured at room temperature for the mechanically alloyed $\mathrm{Ti}_{50}\left(\mathrm{Cu}_{0.45} \mathrm{Ni}_{0.55}\right)_{44-x} \mathrm{Al}_{x} \mathrm{Si}_{4} \mathrm{~B}_{2}$ powders after heating to different temperatures in DSC at a heating rate of $40 \mathrm{~K} / \mathrm{min}$ : (a) $x=0$; (b) $x=4$; (c) $x=8$; (d) $x=12$.

similar to what is known for mechanical alloying of binary alloy systems. ${ }^{20}$ Therefore, a systematic investigation to clarify the detailed mechanism of alloying and amorphization in multicomponent systems is still necessary. The reaction process is likely to depend on the number and mechanical properties (ductile or brittle) of atomic species involved in the system. However, similar to our Ti-based compositions, the amorphous matrices in these three cases all exhibited easily visible supercooled liquid regions. Our results (Table I, Figs. 4 and 6) indicate that despite the residual crystals, the amorphous alloys crystallize through the nucleation and growth of intermetallics at similar temperatures compared with those presumably more uniform melt-spun glasses.

The composite structure composed of amorphous matrix and $\alpha-\mathrm{Ti}$ solution crystal dispersions is unlikely to be a problem for the subsequent consolidation step, as the amorphous matrix is the dominant phase and shows an appreciable supercooled liquid region already similar in width to those observed for undercooled melts. Moreover, the composite nature of the product may be useful in terms of mechanical properties and applications. A number of studies have shown that the presence of (in situ) crystalline or quasicrystalline second phases can strengthen the amorphous alloy and help suppress shear band propagation in a catastrophic fashion. ${ }^{41-45}$ The beneficial second phases contributing to the ductility used so far include the $\beta$ phase in $\mathrm{Zr}-\mathrm{Ti}-\mathrm{Nb}-\mathrm{Cu}-\mathrm{Ni}-\mathrm{Be}$ glass ${ }^{42,43}$ and the fcc $\alpha-\mathrm{Al}$ through primary crystallization in Al-TM-RE glasses. ${ }^{46-48}$ Therefore, the uniform distribution of $\alpha-\mathrm{Ti}$ in the glassy matrix and the absence of any brittle intermetallic crystals may contribute to a desirable combination of strength and ductility for structural applications.

\section{CONCLUSIONS}

Similar to the Zr-based, Fe-based, and Mg-based systems, Ti-based multicomponent amorphous alloys can also be successfully produced through the MA route. A distinct calorimetric glass transition well separated from crystallization event is observed, resulting in a supercooled liquid region as wide as $64 \mathrm{~K}$. The glassy state is reached although MA is a completely different pathway from undercooling of liquids. Al substitution is a useful approach to improve the thermal stability of the supercooled liquid and at the same time reduce the density of the alloy. Although there may be room for further optimization of the composition and processing details, the supercooled liquid region obtained is already comparable in width to the best achieved so far for Ti-based multicomponent glasses form melts and potentially significant for the consolidation of the light weight amorphous alloy to bulk sizes.

Also similar to the Zr-based, Fe-based, and Mg-based systems, Ti-based amorphous alloys contain residual crystals after MA. We have demonstrated a uniform distribution of nanocrystalline crystals with the $\alpha-\mathrm{Ti}$ structure in the amorphous alloy matrix. Such a composite is likely to retain the processing flexibility in the supercooled liquid region and may even be advantageous in terms of eventual mechanical properties. Additional work to consolidate the powders and characterize the mechanical behavior is currently underway.

\section{ACKNOWLEDGMENTS}

The authors gratefully acknowledge the financial support from the National Natural Science Foundation of China under Contract Nos. 59971054 and 50021101. E.M. is indebted to the K.C. Wong Education Foundation, Hong Kong, for supporting his visit to SYNL during this project.

\section{REFERENCES}

1. W.L. Johnson, Mater. Res. Soc. Bull. 24(10), 42 (1999).

2. A. Inoue, Acta Mater. 48, 279 (2000).

3. T. Zhang and A. Inoue, Mater. Trans. JIM 39, 1001 (1998). 
4. A. Inoue, K. Amiya, A. Katsuya, and T. Masumoto, Mater. Trans. JIM 36, 858 (1995).

5. T. Zhang and A. Inoue, Mater. Trans. JIM 40, 301 (1999).

6. T. Zhang and A. Inoue, Mater. Sci. Eng. A 304-306, 771 (2001).

7. N. Nishiyama and A. Inoue, Mater. Trans. JIM 38, 464 (1997).

8. A. Inoue and T. Zhang, Mater. Trans. JIM 37, 185 (1996).

9. W.L. Johnson, Mater. Sci. Forum 225-227, 35 (1996).

10. Y. Kawamura, H. Kato, A. Inoue, and T. Masumoto, Int. J. Powder Metall. 33, 50 (1997).

11. Y. Kawamura, H. Kato, A. Inoue, and T. Masumoto, Appl. Phys. Lett. 67, 2008 (1995).

12. H. Kato, Y. Kawamura, A. Inoue, and T. Masumoto, Mater. Sci. Eng. A 226-228, 458 (1997).

13. K. Amiya, N. Nishiyama, A. Inoue, and T. Masumoto, Mater. Sci. Eng. A 179-180, 692 (1994).

14. M. Seidel, J. Eckert, H-D. Bauer, and L. Schultz, Mater. Sci. Forum 225-227, 119 (1996).

15. D.J. Sordelet, E. Rozhkova, P. Huang, P.B. Wheelock, M.F. Besser, M.J. Kramer, M. Calvo-Dahlborg, and U. Dahlborg, J. Mater. Res. 17, 186 (2002).

16. H. Choi-Yim and W.L. Johnson, Appl. Phys. Lett. 71, 3808 (1997).

17. R.D. Conner, H. Choi-Yim, and W.L. Johnson, J. Mater. Res. 14, 3292 (1999).

18. H. Choi-Yim, R. Busch, U. Köster, and W.L. Johnson, Acta Mater. 47, 2455 (1999).

19. M. Seidel, J. Eckert, and L. Schultz, J. Appl. Phys. 77, 5446 (1995).

20. M. Seidel, J. Eckert, I. Bächer, M. Reibold, and L. Schultz, Acta Mater. 48, 3657 (2000).

21. A. Sagel, R.K. Wunderlich, and H.J. Fecht, Mater. Lett. 33, 123 (1997).

22. R.B. Schwarz and R.R. Petrich, J. Less-Common Met. 140, 171 (1988).

23. L. Battezzati, S. Enzo, L. Schiffini, and G. Cocco, J. LessCommon Met. 145, 301 (1988).

24. C. Politis and W.L. Johnson, J. Appl. Phys. 60, 1147 (1986).

25. M. Baricco, L. Battezzati, I. Soletta, L. Schiffini, and N. Cowlam, Mater, Sci. Eng. A 134, 1398 (1991).

26. B.S. Murty, S. Ranganathan, and M. Mohan Rao, Mater. Sci. Eng. A 149, 231 (1992).

27. K.B. Kim, S. Yi, S.H. Kim, W.T. Kim, and D.H. Kim, Mater. Sci. Eng. A 300, 148 (2001).
28. L.C. Zhang and J. Xu, Mater. Sci. Forum 386-388, 47 (2002).

29. K. Amiya, N. Nishiyama, A. Inoue, and T. Masumoto, Mater. Sci. Eng. A 179-180, 692 (1994).

30. Y-C. Kim, S. Yi, W.T. Kim, and D-H. Kim, Mater. Sci. Forum 360-362, 67 (2001).

31. Y.C. Kim, S. Yi, W.T. Kim, and D.H. Kim, in Supercooled Liquid, Bulk Glassy and Nanocrystalline States of Alloys, edited by A. Inoue, A.R. Yavari, W.L. Johnson, and R.H. Dauskardt (Mater. Res. Soc. Symp. Proc. 644, Warrendale, PA, 2001), p. L4.9.1.

32. U. Köster, Z. Metallkde. 75, 691 (1984).

33. L. Azaroff and M.J. Buerger, The Powder Method in X-Ray Crystallography (McGraw-Hill, New York, 1958), p. 238.

34. Powder Deffraction File No. 18-899, International Centre for Diffraction Data, Newton Square, PA.

35. E. Bonetti, G. Cocco, S. Enzo, and G. Valdré, Mater. Sci. Technol. 6, 1258 (1990).

36. E. Bonetti, G. Valdré, S. Enzo, and G. Cocco, J. Alloys Compd. 194, 331 (1993).

37. G. Cocco, I. Soletta, L. Battezzati, M. Baricco, and S. Enzo, Philos. Mag. B 61, 473 (1990).

38. N. Schlorke, J. Eckert, and L. Schultz, Mater. Sci. Eng. A 226-228, 425 (1997).

39. M. Seidel, J. Eckert, E. Zueco-Rodrigo, and L. Schultz, J. NonCryst. Solids 205-207, 514 (1996).

40. N. Schlorke, J. Eckert, and L. Schultz, Mater. Sci. Forum 269-272, 761 (1998).

41. C.C. Hays, C.P. Kim, and W.L. Johnson, Phys. Rev. Lett. 84, 2901 (2000).

42. F. Szuecs, C.P. Kim, and W.L. Johnson, Acta Mater. 49, 1507 (2001).

43. E. Pekarskaya, C.P. Kim, and W.L. Johnson, J. Mater. Res. 16, 2513 (2001).

44. A. Inoue, T. Zhang, and Y.H. Kim, Mater. Trans. JIM 38, 749 (1997).

45. A. Inoue, T. Zhang, M.W. Chen, and T. Sakurai, J. Mater. Res. 15, 2195 (2000).

46. Y.H. Kim, A. Inoue, and T. Masumoto, Mater. Trans. JIM 32, 599 (1991).

47. A. Inoue, Y.H. Kim, and T. Masumoto, Mater. Trans. JIM 33, 487 (1992).

48. G.S. Choi, Y.H. Kim, H.K. Cho, A. Inoue, and T. Masumoto, Scr. Metall. Mater. 33, 1301 (1995). 